\title{
Effects of Calcium Aluminate Compounds on Hydration of BFS
}

\author{
Hyeon-jin Song*****, Seung-Min Kang******, Se-Hoon Jeon*******, \\ Jung-Won Kim***, and Myong-Shin Song****† \\ *Department of Advanced Energy\&Chemical Engineering, Kangwon National University, Samcheok 25913, Korea \\ **Department of Advanced Materials Engineering, Kangwon National University, Samcheok 25913, Korea \\ ${ }^{* * *}$ Research Center of Advanced Convergence Processing on Materials, Kangwon National University, \\ Samcheok 25913, Korea
}

(Received July 10, 2015; Revised August 20, 2015; Accepted September 30, 2015)

\begin{abstract}
Blast furnace slag(BFS) is well known for its hardening mechanism in ordinary Portland cement with alkali activation due to its latent hydraulic property. The possibility of using calcium compound as activator for BFS has been investigated in this study. The hydration properties of calcium compound activated BFS binders were explored using heat of hydration, powder X-ray diffraction and compressive strength testing. Heat of hydration results indicate that the hydration heat of BFS is lower than OPC paste by about $50 \%$. And ettringite as hydration product was formed continuously as the calcium sulfate was decreased. The maximum compressive strength of hardened BFS mortar at 28 days is confirmed to be $83 \%$ as compared with hardened OPC mortar.
\end{abstract}

Key words : Blast furnace slag, BFS hydrate, Ettringite, Calcium aluminate compounds, Non-OPC

\section{Introduction}

$\mathrm{G}$ lobal warming due to greenhouse gases is causing climate changes and abnormal climates, and global efforts including signing of climate change treaty such as Kyoto protocol and $\mathrm{CO}_{2}$ regulation, etc. across the whole industry in each country are being made to solve this problem. Particularly, for $\mathrm{CO}_{2}$ produced by cement industry, there is the result of about $870 \mathrm{~kg}$ of it being discharged in manufacturing 1 ton of Portland cement. ${ }^{1)}$ Such discharge of $\mathrm{CO}_{2}$ accounts for about $5 \%$ of the whole industry, which may be considered to be a very large amount of discharge. Therefore, in the cement industry, fly ash, blast furnace slag, etc. are utilized in substitution as the admixture to reduce usage of cement with a goal of reduction in $\mathrm{CO}_{2}$ produced upon cement manufacturing. Blast furnace slag is a representative byproduct produced upon manufacturing of pig iron in the steel industry, where vitreous blast furnace slag is discharged by quenching after adding a large quantity of pressurized water to the blast furnace slag in molten condition as obtained from cokes, iron ores, limestone. In the blast furnace slag, the combined composition of $\mathrm{SiO}_{2}, \mathrm{Al}_{2} \mathrm{O}_{3}$, $\mathrm{CaO}, \mathrm{MgO}$ accounts for about $97 \%$, and efforts for improvement are required ${ }^{2)}$ as the problems of insufficient manifestation of initial hydration characteristics in hardened paste

Corresponding author : Myong-Shin Song

E-mail : msong0422@kangwon.ac.kr

Tel : +82-33-570-6558 Fax : +82-33-570-6558 occurs when used as a mixture with cement because of obstruction of iron elution due to formation of $\mathrm{ASH}_{6}$ film upon mixing with water. While a variety of methods for activation of blast furnace slag are being studied, most studies are hinged upon utilization plans as a substitution material for cement or admixture for cement through high curing temperatures, activation methods using a strong alkali, etc. In the studies on alkali activity, problems of high shrinkage and weathering, etc. are being presented, where the greatest problem involves cancellation of advantages for use of blast furnace slag by generation of $\mathrm{CO}_{2}$ and energy produced upon manufacturing of alkali activation agents. ${ }^{3-4)}$ For this reason, a variety of studies are being implemented to replace alkali activation agents. Mun et $\mathrm{al}^{5)}$ affirmed manifestation of excellent strengths and shrinkage compensation by adding limestone and anhydrous gypsum to the blast furnace slag, and diversified studies on gypsum addition are similarly in progress. ${ }^{6)}$ Therefore, in the present study, hydrate analysis for initial curing periods along with the study on compressive strength characteristics were conducted to observe physical characteristics for the effects of the ettringite generated by addition of Calcium Aluminate compounds as a method to improve initial hydration characteristics of the blast furnace slag on hydration of hardened paste of the blast furnace slag.

\section{Experimental Procedure}

\subsection{Experimental materials}

For the blast furnace slag employed in the present study, 
Table 1. The Mixing Ratios of CSA and CA

\begin{tabular}{cccc}
\hline & W/B & Fluidized bed boiler ash & Alumina dust \\
\hline CSA & \multirow{2}{*}{0.8} & 60 & 40 \\
CA & & 50 & 50 \\
\hline
\end{tabular}

Table 2. Chemical Composition of Material

\begin{tabular}{ccccccccc}
\hline Unit(\%) & $\mathrm{CaO}$ & $\mathrm{SiO}_{2}$ & $\mathrm{Al}_{2} \mathrm{O}_{3}$ & $\mathrm{SO}_{3}$ & $\mathrm{MgO}$ & $\mathrm{TiO}_{2}$ & $\mathrm{~K}_{2} \mathrm{O}$ & $\mathrm{Fe}_{2} \mathrm{O}_{3}$ \\
\hline BFS & 38.02 & 35.23 & 15.73 & 5.15 & 4.26 & 0.47 & 0.35 & 0.25 \\
OPC & 61.5 & 20.6 & 5.39 & 2.17 & 0.15 & 0.34 & 1.04 & 2.91 \\
$\mathrm{CSA}$ & 44.8 & 1.40 & 37.8 & 13.2 & 0.291 & 0.039 & 0.101 & 0.357 \\
$\mathrm{CA}$ & 50.6 & 9.28 & 26 & 2.69 & 7.65 & 0.344 & 0.0143 & 1.82 \\
\hline
\end{tabular}

3 types of blast furnace slag(BFS) fine powders in compliance with KS F 2563 were used, while ordinary Portland cement(OPC) of type 1 in compliance with KS L 5201 was used. For Calcium Aluminate Compounds(to be denoted as 'CAC' hereafter), Calcium Sulfo-Aluminate(to be denoted as 'CSA' hereafter) and Calcium Aluminate(to be denoted as 'CA' hereafter) synthesized independently by the laboratory were used, while reagent grades were used for $\mathrm{CaO}$ and $\mathrm{CaSO}_{4}$. The synthesis ratios for CSA and CA are shown in Table 1 , and the synthesized results were obtained by firing under the condition of maintaining at $1300^{\circ} \mathrm{C}, 1000^{\circ} \mathrm{C}$ for 30 minutes using an electric furnace, respectively. Chemical characteristics of each material used are shown in Table 2.

\subsection{Experimental procedure}

\subsubsection{Calcium Aluminate Compounds}

In the present study, to promote the hydration reaction of $\mathrm{BFS}$, the effects of ettringite $\left(3 \mathrm{CaO} \cdot \mathrm{Al}_{2} \mathrm{O}_{3} \cdot 3 \mathrm{CaSO}_{4} \cdot 32 \mathrm{H}_{2} \mathrm{O}\right)$ produced by reaction with $\mathrm{CAC}$ and $\mathrm{CaO}, \mathrm{CaSO}_{4}$ were reviewed with focus. For mixing of admixture, the ratio for CSA and CA was derived by calculation of the ratios of $\mathrm{CaO}$ and $\mathrm{SO}_{3}$ to $\mathrm{Al}_{2} \mathrm{O}_{3}$ for the optimum condition to produce ettringite, while the deficient amounts of $\mathrm{CaO}$ and $\mathrm{SO}_{3}$ were supplemented by incorporating reagent grades of $\mathrm{CaO}$ and $\mathrm{CaSO}_{4}$. To check for hydration products of the admixture itself, X-ray diffraction analysis results for the admixtures A1 and A2 are shown in Fig. 1 and 2, respectively. The mixing ratios for admixtures A1 and A2 are shown in Table 3. According to the X-ray diffraction analysis results for admixtures A1 and A2, most ettringite was affirmed to be produced from the initial $3 \mathrm{~h}$, and the peaks of monosulfate were also observed.

\subsubsection{Measurement of compressive strength}

To check for compressive strength characteristics of BFS hardened paste due to production of Ettringite, measurements were conducted based on compressive strength test method for cement in KS L ISO 679, where the ratio of water and binder(W/B) was set to be 0.5 and that of sand and binder $(\mathrm{S} / \mathrm{B})$ to be 3.0 in production of specimens for measurement of compressive strengths. The mixing ratios are shown in Table 4. Since workability of SA2 is not

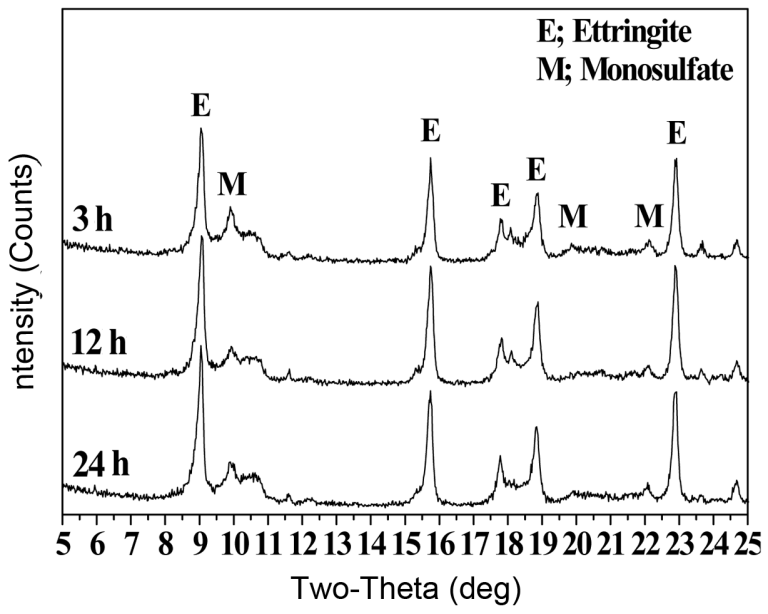

Fig. 1. X-ray diffraction analysis results of the hardened admixture; A1.

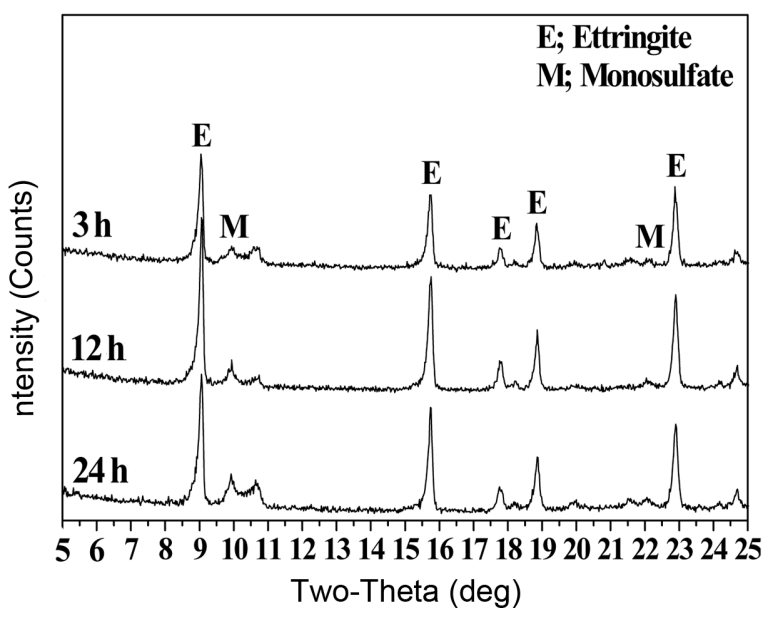

Fig. 2. X-ray diffraction analysis results of the hardened admixture; A2.

secured by quick setting of CA, $0.1 \%$ of citric acid was added as an additive. The mixed mortar was injected in a prismatic mold of $40 \times 40 \times 160 \mathrm{~mm}$ in size, and the hardened paste was separated from the mold $24 \mathrm{~h}$ later. All specimens were subjected to sealed curing at the temperature of $21^{\circ} \mathrm{C}$ before each test, and compressive strengths were measured

Table 3. The Mixing Ratios of Activator

\begin{tabular}{ccccc}
\hline & \multicolumn{4}{c}{ Activator } \\
\cline { 2 - 5 } & $\mathrm{CSA}$ & $\mathrm{CA}$ & $\mathrm{CaO}$ & $\mathrm{CaSO}_{4}$ \\
\hline $\mathrm{A} 1$ & 50 & & 7.5 & 42.5 \\
$\mathrm{~A} 2$ & & 72.5 & & 27.5 \\
\hline
\end{tabular}

Table 4. The Mixing Ratios of BFS Paste and Mortar

\begin{tabular}{cccccccc}
\hline & \multirow{2}{*}{ W/B } & \multirow{2}{*}{ S/B } & \multirow{2}{*}{ BFS } & \multicolumn{4}{c}{ Activator } \\
\cline { 5 - 7 } & & & & OPC & A1 & A2 & Additive \\
\hline SC & & & & 20 & & & \\
SA1 & 0.5 & 3.0 & 80 & & 20 & & \\
SA2 & & & & & & 20 & 0.1 \\
\hline
\end{tabular}


Table 5. Curing Times for Paste

\begin{tabular}{cc}
\hline Sample type & Curing time \\
\hline Admixture & $3 \mathrm{~h}, 12 \mathrm{~h}, 24 \mathrm{~h}$ \\
\hline Blast furnace slag & $3 \mathrm{~h}, 6 \mathrm{~h}, 12 \mathrm{~h}, 18 \mathrm{~h}$, \\
+ Admixture & 1 day, 3 day, 7 day \\
\hline
\end{tabular}

at the material ages of $1,3,7,14,28$ days, respectively.

\subsubsection{Simplified measurement of hydration heat}

To observe the effects of BFS on initial hydration reaction as a function of formulation types, simplified measurement of hydration heat was conducted. The BFS paste mixed with the W/B of 0.5 was injected in the insulated container produced independently and sealed, for which hydration heat generation was measured for $72 \mathrm{~h}$ at an interval of $1 \mathrm{sec}$ using DATA LOGGER (Ucam- 60b, Kyowa Co., Japan) of 10-point type.

\subsubsection{Analysis of hydrates}

Hydrate analysis for BFS hardened paste was aimed at pastes as the object with W/B set to be 0.5. The mixed paste was cured under sealing in a circular plastic frame, with the curing periods shown in Table 5. To analyze microstructures for hydrates at each material age, the hardened paste was held in hydration by acetone after being pulverized and then used for analysis. The X-ray diffraction analysis to check for hydration products at each material age was conducted for 2 theta of $5 \sim 80^{\circ}$ under the condition of $4^{\circ} / \mathrm{min}$.

\section{Results and Discussion}

\subsection{Simplified measurement of hydration heat}

Simplified measurement results of hydration heat for BFS hardened paste mixed with $\mathrm{CAC}$ are shown in Fig. 3. In comparison with heat generation temperature of OPC, the BFS hardened paste showed generally low heat generation temperatures. While the second hydration reaction heat was affirmed for SA1, the first reaction heat within initial $2 \mathrm{~h}$ is considered to be caused by the reaction of the added $\mathrm{CaO}$, and the second reaction heat at $44.3^{\circ} \mathrm{C}$ after elapse of $16 \mathrm{~h}$ is considered as the overlapping of the reaction heat while production of ettringite is continuously maintained for about $16 \mathrm{~h}$ after $6 \mathrm{~h}$. SA2 showed the lowest temperature of $37^{\circ} \mathrm{C}$ after about $14 \mathrm{~h}$ among BFS hardened pastes. This appears to indicate that a relatively low temperature is shown since there is no reaction heat for $\mathrm{CaO}$ in comparison with $\mathrm{SA} 1$, although ettringite is rapidly produced in SA2. also While OPC showed the highest heat generation after about $14 \mathrm{~h}$, SC showed the low temperature of $46.9^{\circ} \mathrm{C}$ after $28 \mathrm{~h}$. As compared with the heat generation temperature of OPC, hydration of BFS alone can be affirmed not to proceed, while BFS hardened paste with CAC used as the activation agent showed generally lower temperatures as compared with OPC. Although hydration does not proceed in BFS even after elapse of a given time, hydration can be seen to

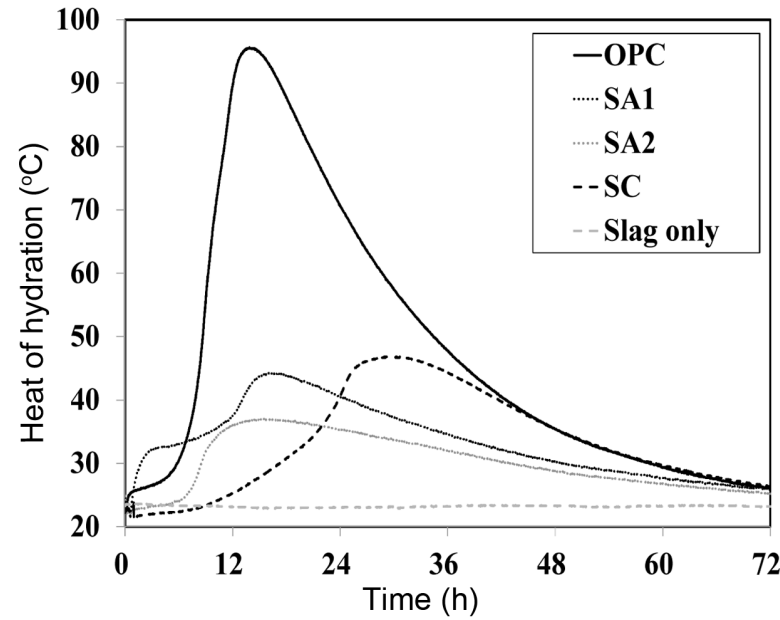

Fig. 3. Heat of hydration of BFS paste with different admixture.

proceed in BFS hardened paste with CSA or CA added as the activation agent.

\subsection{Hydrate analysis results for hardened paste of blast furnace slag}

While CSA produces mainly ettringite and monosulfate by hydration reaction, CA produces ettringite under the presence of $\mathrm{SO}_{3}{ }^{7-8)} \mathrm{X}$-ray diffraction analysis results for BFS hardened paste with incorporation of $\mathrm{A} 1, \mathrm{~A} 2$ admixtures and OPC are shown in Fig. 4. In both SA1 and SA2, production of ettringite within $3 \mathrm{~h}$ can be affirmed, and the peaks of remaining gypsum dihydrate can be ascertained. Such peaks of gypsum dihydrate are considered to appear due to the reaction of anhydrous gypsum remaining after production of ettringite with mixing water. While very weak peaks of ettringite can be affirmed to begin to appear in SC after $6 \mathrm{~h}$, this is considered attributable to $20 \mathrm{wt} \%$ of OPC mixed in BFS with the amount of ettringite producible by $20 \mathrm{wt} \%$ OPC being relatively small so that hydration reaction is weak, and the peaks of ettringite can be affirmed to appear clearly after $12 \mathrm{~h}$ of hydration required for occurrence of sufficient hydration. The peaks of monosulfate which appeared in hydrates of admixtures A1, A2 alone were not affirmed in BFS hardened paste containing each admixture.

Shown in Fig. 5 are the X-ray diffraction analysis results for hydration periods of $1,3,7$ days in BFS hardened paste. As the hydration progressed, the intensity values of anhydrous gypsum peaks of SA1, SA2 showed a decreasing tendency. This is considered to indicate that the peaks for anhydrous gypsum are reduced by continuous production of ettringite due to reaction of $\mathrm{SO}_{3}$ and CSA, CA in BFS hardened paste. In SC using $20 \mathrm{wt} \%$ OPC as the admixture, anhydrous gypsum peaks of a small intensity could be observed. These are considered as the peaks due to a trace of gypsum used as a pulverization agent in processing process of BFS, and the fact that anhydrous gypsum peaks are not observed after 3 days is attributed to the consumption 

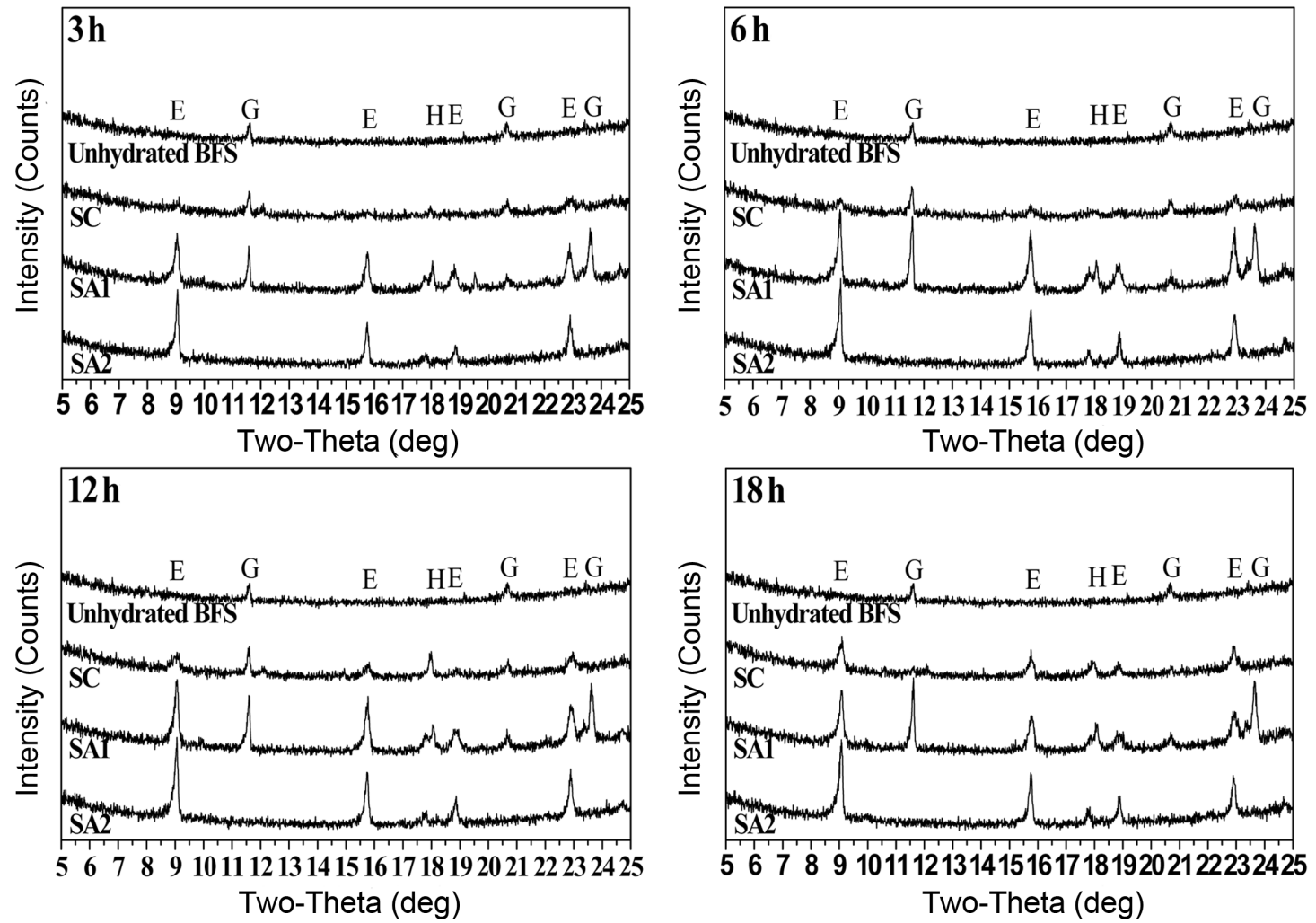

Fig. 4. X-ray diffraction analysis results of hardened BFS at curing age of $3 \mathrm{~h}, 6 \mathrm{~h}, 12 \mathrm{~h}$ and $18 \mathrm{~h}$; E- Ettringite, G-Gypsum dihydrate, H-Calcium hydroxide.
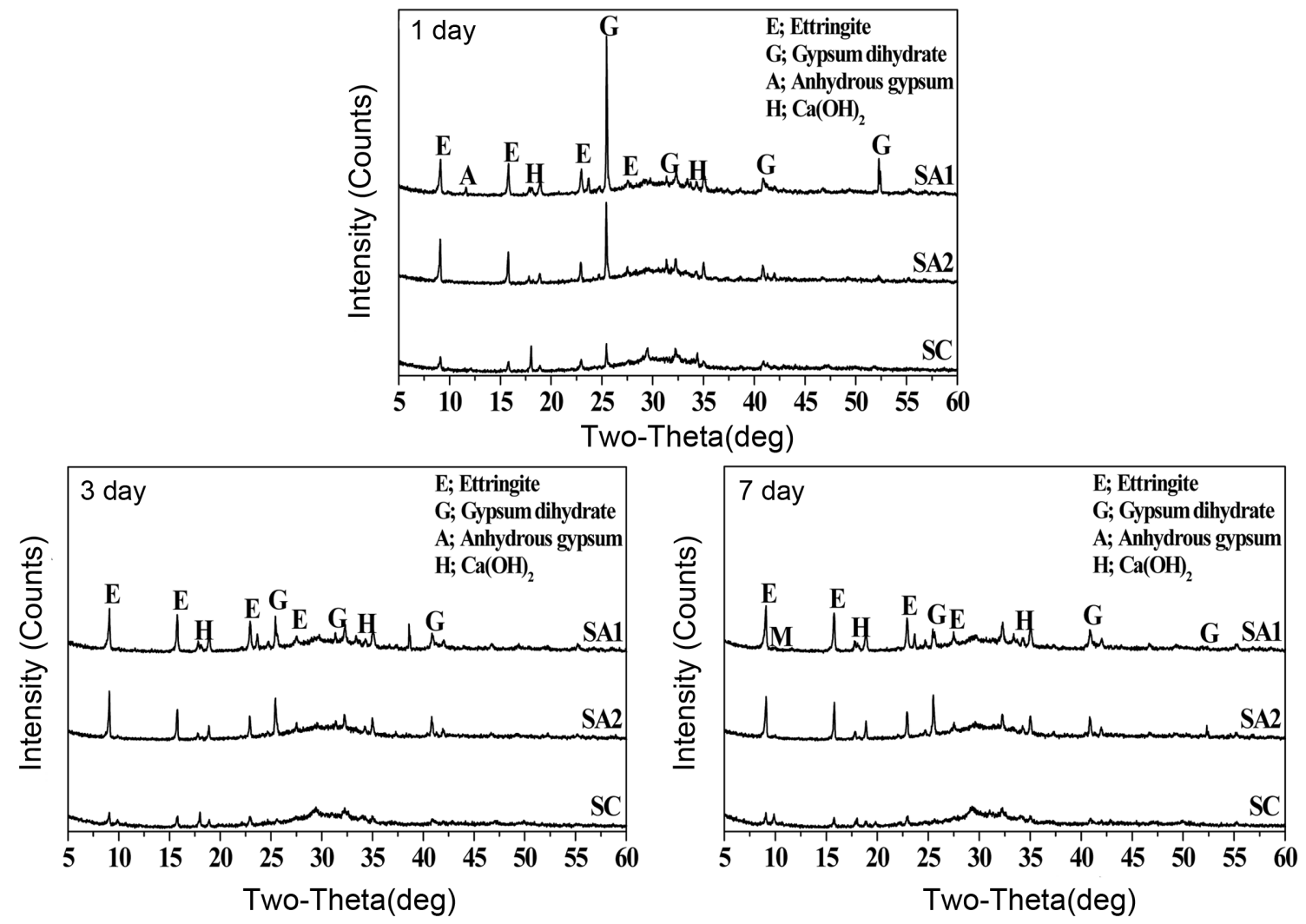

Fig. 5. X-ray diffraction analysis results of hardened BFS at curing age of 1 day, 3 day and 7 day. 

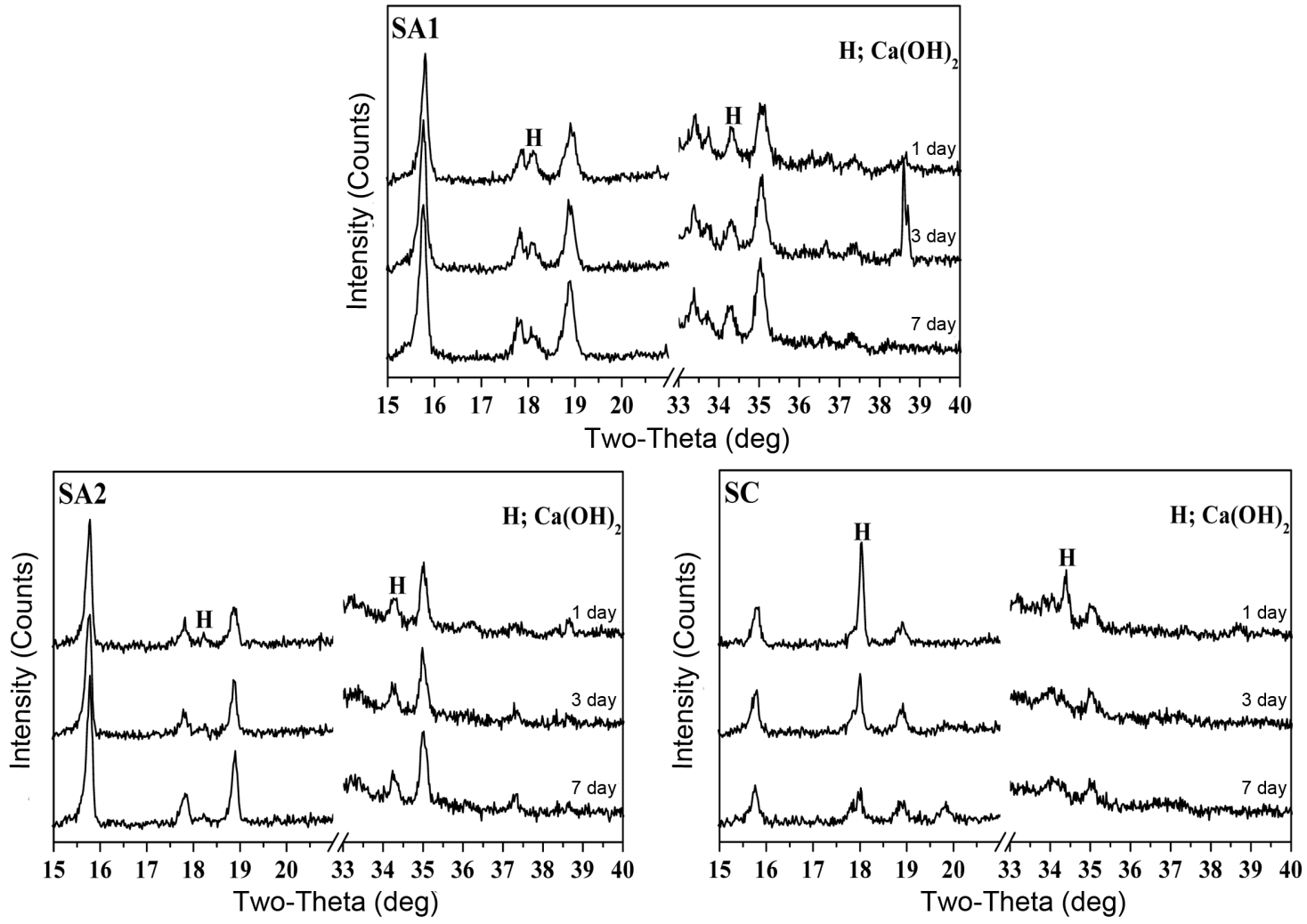

Fig. 6. X-ray diffraction analysis results of hardened BFS; Main peak is $\mathrm{Ca}(\mathrm{OH})_{2}$.

while producing ettringite by reaction between gypsum contained in BFS and $\mathrm{C}_{3} \mathrm{~A}$ in OPC. Shown in Fig. 6 are the results of observing the peaks of $\mathrm{Ca}(\mathrm{OH})_{2}$ in each hardened past. While the peaks of $\mathrm{Ca}(\mathrm{OH})_{2}$ appear strongly SC, reduction in intensity of the peaks with elapse of the material age can be affirmed, which is attributed to the consumption of the peaks of $\mathrm{Ca}(\mathrm{OH})_{2}$ due to conversion to some other phase. Since $20 \mathrm{wt} \%$ of OPC is contained in $\mathrm{SC}, \mathrm{Ca}(\mathrm{OH})_{2}$ peaks from the contained OPC are considered to have appeared at an early stage of hydration. While the peak intensities of $\mathrm{Ca}(\mathrm{OH})_{2}$ for SA1 and SA2 were shown to be lower than those for SC containing $20 \mathrm{wt} \%$ OPC, this is attributed to the small amount of $\mathrm{Ca}(\mathrm{OH})_{2}$ produced by the contained CAC. Also, the peak intensity of $\mathrm{Ca}(\mathrm{OH})_{2}$ for $\mathrm{SA} 2$ is shown to be lower than that of $\mathrm{Ca}(\mathrm{OH})_{2}$ for $\mathrm{SA} 1$, which may signify that production of $\mathrm{Ca}(\mathrm{OH})_{2}$ may be shown differently due to composition of the compound even if CAC of the similar formulation was used for production of ettringite. In addition, when compared with the above heat generation characteristics of hydration, the heat generation characteristics of hydration can be seen to have a close relationship with $\mathrm{Ca}(\mathrm{OH})_{2}$ generation in the hardened paste.

\subsection{Measurement results of compressive strength}

Compressive strength results for BFS hardened paste with substitution of admixtures are shown in Fig. 7. At the material age of 28 days, compressive strengths of SA1, SA2, SC were shown to be about $83 \%, 58 \%, 54 \%$, respectively, in

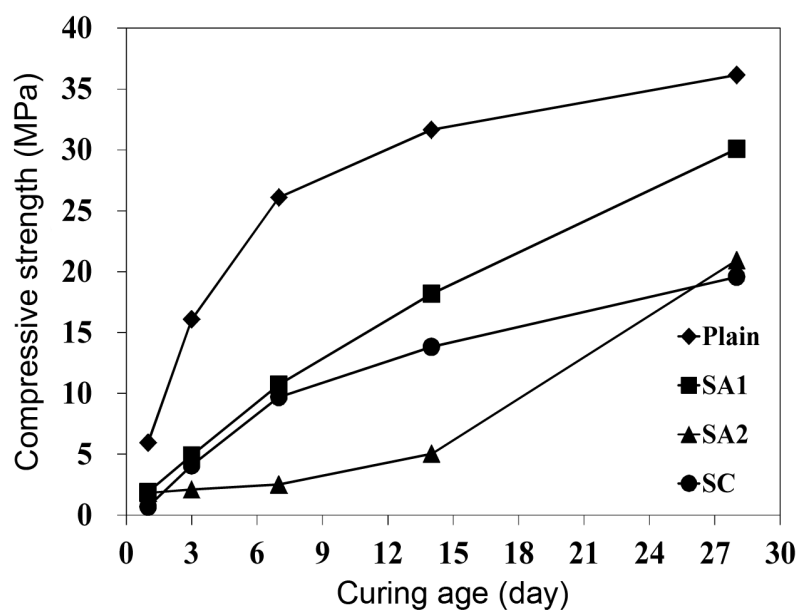

Fig. 7. Compressive strength results of hardened BFS with admixture and hardened OPC.

comparison with those of OPC. In terms of compressive strength of the initial 1 day, all BFS hardened pastes showed similar strengths, with the compressive strength for SA1 being the highest. Kim et $\mathrm{al}^{9)}$ have reported that addition of $\mathrm{CaO}$ to BFS showed manifestation of the higher strength than that of $\mathrm{Ca}(\mathrm{OH})_{2}$ frequently used as an alkali activation agent. The fact that the compressive strength for SA1 at the material age of 1 day was the highest is considered to be due to the effect of alkali activation by $\mathrm{CaO}$ added 
along with CSA. Although SA2 showed manifestation of low strengths until the material age of 14 days, drastic strength manifestation was exhibited after 14 days. Manifestation of low compressive strengths at early stages of hydration is considered to be related to production of $\mathrm{Ca}(\mathrm{OH})_{2}$ at early stages of hydration, and manifestation rates for compressive strength may be analyzed to be low since production of $\mathrm{Ca}(\mathrm{OH})_{2}$ was weak at early stages of hydration. Drastic manifestation of compressive strengths after the material age of 14 days is considered to reflect that CA added as the admixture for BFS governed the strength, and that drastic manifestation of strengths was realized by promotion of hydration by BFS after 14 days. Although SC showed similar manifestation of strength to that for SA1 at the material age of 1 day, the manifestation rates of compressive strength were shown to be lowered after the material age of 7 days. This suggests that although compressive strength was governed by OPC at an early stage of hydration, control power of OPC for manifestation of compressive strengths was weakened after elapse of a given time so that compressive strength was manifested by hydration of BFS alone since the incorporated amount of $20 \mathrm{wt} \%$ of OPC as the admixture for activation of BFS was very small. This may also be analyzed from the lowered existence of $\mathrm{Ca}(\mathrm{OH})_{2}$ by the material age of 7 days as shown in the X-ray diffraction analysis results.

\section{Conclusions}

In the present study, CAC inducing production of ettringite was synthesized for use as the activation agent for initial promotion of hydration of BFS. According to the analysis results for hydration heat generation of BFS hardened paste, hydrates and measurement of compressive strengths, the following conclusions have been obtained.

1) Hydration heat of BFS hardened paste due to CAC is considered to be the heat generation resulting from overlap- ping of temperatures while the initially produced ettringite continued to be maintained.

2) In SA1 and SA2 with addition of CAC among BFS hardened pastes, clear production of ettringite within initial $3 \mathrm{~h}$ could be affirmed, while weak ettringite peaks could be ascertained beginning with $6 \mathrm{~h}$ in the case of SC. Also, compressive strengths of SA1 were maintained for a long period after production of $\mathrm{Ca}(\mathrm{OH})_{2}$, which is considered to have provided BFS with a sufficient stimulus.

\section{REFERENCES}

1. C. W. Park, "Eco-Friendly of Concrete," J. Korea Concrete Institute, 20 [6] 24-6 (2008).

2. S. H. Lee, "Hydration Mechanism of Ground Granulated Blast Furnace Slag," J. Korea Concrete Institute, 24 [6] 31-4 (2012).

3. F. Bellmann, "Activation of Blast Furnace Slag by a New Method," Cem. Concr. Res., 39 [8] 644-50 (2009).

4. J. I. Escalante-Garcia, "Portland Cement-blast Furnace Slag Mortars Activated Using Waterglass: Effect of Temperature and Alkali Concentration," Const. Build. Mater., 66 [15] 323-28 (2014).

5. K. J. Mun, "The Effect of Slaked Lime, Anhydrous Gypsum and Limestone Powder on Properties of Blast Furnace Slag Cement Mortar and Concrete," Const. Build. Mater., 21 [7] 1576-82 (2007).

6. H. Sakamoto, "pH Behavior of Hydrated Low-Alkalinity Cement," J. Nucl. Fuel Cycle Environ., 5 [2] 37-42 (1999).

7. F. Winnefeld, "Hydration of Calcium Sulfo-Aluminate Cements - Experimental Findings and Thermodynamic Modelling," Cem. Concr. Res., 40 [8] 1239-47 (2010).

8. K. Arbi, "Alkali-Activated Blends of Calcium Aluminate Cement and Slag/Diatomite," Ceram. Int., 39 [8] 9237-45 (2013).

9. M. S. Kim, "Use of $\mathrm{CaO}$ as an Activator for Producing a Price-competitive Non-cement Structural Binder using Ground Granulated Blast Furnace Slag," Cem. Concr. Res., 54 208-14 (2013). 